\title{
Cardiac surgery-associated acute kidney injury (CSA-AKI) in adults and pediatrics; prevention is the optimal management.
}

\author{
Abdulaziz Alghamdi ${ }^{1}$, Mohammed O. Aqeeli ${ }^{1}$, Saud Muhaisin Altalhi Q ${ }^{1}$, Fahad Khaled \\ Alshammari $\mathrm{M}^{1}$, Abdullah Mohammed Bajebair $\mathrm{A}^{1}$, and Khalid $\mathrm{Al}_{e}$ brahim $^{1}$ \\ ${ }^{1}$ King Abdulaziz University Hospital
}

December 16, 2021

\begin{abstract}
Background Cardiac surgery-associated acute kidney injury (CSA-AKI) is an important and serious complication that affects morbidity and mortality. We studied both pediatric and adults using the definition of the Acute Kidney Injury Network (AKIN). Methods This is an observational retrospective cohort study done at King Abdulaziz University Hospital in Jeddah, Saudi Arabia approved by ethical committee. The exclusion criteria were baseline serum creatinine (SCr) [?] $4 \mathrm{mg} / \mathrm{dL}$ or preexisting renal failure requiring dialysis, reoperation, death within 24 hours postoperatively, and operative mortality or missing data. 941 patients were included in the analysis using the statistical software SPSS, version 15.0. Results $28.68 \%$ in the adult group and $20.07 \%$ in the pediatric group developed CSA-AKI. Adult risk factors included age group of 60-69 years, cardiopulmonary bypass (CPB), number of grafts and hypertension. In the pediatric group, CPB, aortic cross-clamping (ACX) and the lower preoperative $\mathrm{SCr}$ are the main risk factors Conclusion Conventional conservative management and preoperative Identification of predictor risk factors are essential for prevention of CSA-AKI which constitute the main strategy for optimal management.
\end{abstract}

Cardiac surgery-associated acute kidney injury (CSA-AKI) in adults and pediatrics; prevention is the optimal management.

Abdulaziz A. Alghamdi MBBS, Mohammed O. Aqeeli MBBS, Saud Muhaisin Q Altalhi MBBS, Fahad Khaled M Alshammari MBBS, Abdullah Mohammed A Bajebair MBBS, Khaled Ebrahim Al-Ebrahim MBBCh,FRCSC.

Department of surgery, King Abdulaziz University, Jeddah, Saudi Arabia

Correspondence

Mohammed O Aqeeli, MBBS, Jedaah, Saudi Arabia

E-mail: moa.aqeeli@gmail.com and maqeeli0005@stu.kau.edu.sa

ORCID

Khaled Ebrahim Al-Ebrahim

https://orcid.org/0000-0003-0502-4741

Abdulaziz A. Alghamdi

https://orcid.org/0000-0002-1402-5001

Mohammed O. Aqeeli

https://orcid.org/0000-0002-6946-4773 


\section{Abstract \\ Background}

Cardiac surgery-associated acute kidney injury (CSA-AKI) is an important and serious complication that affects morbidity and mortality. We studied both pediatric and adults using the definition of the Acute Kidney Injury Network (AKIN).

\section{Methods}

This is an observational retrospective cohort study done at King Abdulaziz University Hospital in Jeddah, Saudi Arabia approved by ethical committee. The exclusion criteria were baseline serum creatinine ( $\mathrm{SCr}$ ) [?] $4 \mathrm{mg} / \mathrm{dL}$ or preexisting renal failure requiring dialysis, reoperation, death within 24 hours postoperatively, and operative mortality or missing data. 941 patients were included in the analysis using the statistical software SPSS, version 15.0.

\section{Results}

$28.68 \%$ in the adult group and $20.07 \%$ in the pediatric group developed CSA-AKI. Adult risk factors included age group of 60-69 years, cardiopulmonary bypass (CPB), number of grafts and hypertension. In the pediatric group, $\mathrm{CPB}$, aortic cross-clamping (ACX) and the lower preoperative $\mathrm{SCr}$ are the main risk factors

ConclusionConventional conservative management and preoperative Identification of predictor risk factors are essential for prevention of CSA-AKI which constitute the main strategy for optimal management.

Introduction

Acute kidney injury (AKI) is a rapid deterioration of glomerular filtration rate (GFR) that is associated with significant impairment of renal function. CSA-AKI is reported in up to $30 \%$ and considered an independent risk factor for increased morbidity and mortality causing dialysis in up to $4 \%^{1-4}$. Slight increase of $(0.3-0.5$ $\mathrm{mg} / \mathrm{dL}$ ) in $\mathrm{SCr}$ is significantly correlated to an increase in 30-days mortality ${ }^{5}$. CSA-AKI is the second cause of AKI in intensive care units (ICU) preceded by sepsis increasing the death by fourfold reaching up to $8 \%^{6-7}$. Mortality associated with renal replacement therapy (RRT) reaches up to $63 \%^{8}$. It is known that hypertension, advanced age, hyperlipidemia, and peripheral vascular disease are nonmodifiable risk factors for $\mathrm{AKI}^{9}$. Uniquely among surgeries, cardiac surgery has some properties that increase the risk of AKI such as $\mathrm{CPB}$, ACX, high rates, and volumes of exogenous blood product transfusion and high doses of vasopressors ${ }^{10}$. Fortunately, many CSA-AKI risk factors can be modified. Identifying risk factors is one of the most important strategies to prevent or minimize CSA-AKI.

Methodology

This is an observational retrospective cohort study done at KAUH Jeddah, SA approved by KAUH ethical committee. 1265 patients underwent cardiac surgery between January 2016 and December 2020. CSA-AKI was defined for pediatric and adult groups by AKIN as an increase in $\mathrm{SCr}$ of [?] $0.3 \mathrm{mg} / \mathrm{dL}$ above baseline that persisted for more than 48 hours postoperatively. Also, it classifies CSA-AKI into 3 stages $^{11}$. (Table 1) The exclusion criteria were: baseline $\mathrm{SCr}$ [?] $4 \mathrm{mg} / \mathrm{dL}$ or preexisting renal failure requiring dialysis, reoperation, death within 24 hours postoperatively, and operative mortality or missing data. 941 patients were included in the analysis using the statistical software SPSS, version 15.0. Mann-Whitney test was used in univariate analysis of continuous variables and the Person Chi-square test or Fisher's exact test was used to analyze categorical variables.

(Table 1): Acute Kidney Injury Network (AKIN) criteria.

\begin{tabular}{lll}
\hline Acute Kidney Injury Network & Acute Kidney Injury Network & Acute Kidney Injury Network \\
(AKIN) criteria. & (AKIN) criteria. & (AKIN) criteria. \\
Stage & Serum Creatinine & Urine Output
\end{tabular}


$<0.5 \mathrm{~mL} / \mathrm{kg} / \mathrm{h}$ for $6 \mathrm{~h}$

[?]150-200\% (1.5-2-fold) from

baseline

3a a Patients receiving renal replacement therapy are included in Stage 3. from baseline

Increase $>300 \%$ ( $>3$-fold) from

baseline, or Serum creatinine to

$>4 \mathrm{mg} / \mathrm{dL}$ with an acute Increase of $[?] 0.5 \mathrm{mg} / \mathrm{dL}$

\section{Statistical analysis}

Continuous variables are presented as medians and 25-75, (25-75 median percentiles) as data were not normally distributed and categorical variables are expressed as frequencies and percentages. Mann-Whitney test was used in univariate analysis of continuous variables and the Person Chi-square test or Fisher's exact test was used to analyze categorical variables.

Results

Table 2 showed the demographic and clinical characteristics of pediatric patients who were subjected to cardiac surgery. Those were divided into 2 groups according to the occurrence of acute kidney injury, most of all pediatric patients were in age group $>30$ days- [?]2 years $(\mathrm{n}=329,57.9 \%)$, and least was [?] $13-<18$ years $(\mathrm{n}=31,5.5 \%)$. The males were greater than females $(54.9 \%$ versus $45.1 \%)$; Non-Saudi patients were more than Saudi $(82.4 \%$ versus $17.6 \%)$. The same distributions of age, gender, and nationality were found in patients with and without AKI with insignificant differences between them $(\mathrm{P}=0.092, \mathrm{P}=0.600$, and $\mathrm{P}$ $=0.784$, respectively). The median of $\mathrm{CPB}$ and ACX durations were 68 and 48 min that was significantly prolonged in patients with AKI versus those without AKI (79 versus 64 min and 57 versus 45, $\mathrm{P}<0.0001$ for both). Case urgency was mostly elective than emergent in all patients ( $82.6 \%$ versus $17.4 \%)$ and the same distribution in patients with and without AKI. Regarding creatinine levels, preoperative SCr was significantly higher in patients without AKI versus those with AKI $(\mathrm{P}<0.0001)$, meanwhile, post-operative creatinine levels, the difference between post- and pre-operative creatinine, and percentage changes of creatinine were significantly lower in patients without AKI versus patients with AKI $(\mathrm{P}<0.0001$ for all). Stages of AKI were stage I (54.4\%), then stage II (30.7\%), and lastly stage III (14.9\%). Death within index hospitalization was significantly higher in patients with AKI versus those without ( $7 \%$ versus $1.5 \%, \mathrm{P}=0.004)$.

Table 3 showed the demographic and clinical characteristics of adult patients who were subjected to cardiac surgery. The patients were divided into 2 groups according to the occurrence of acute kidney injury, Adult patients who developed AKI were found in the age group 60-69 years; while those who did not develop AKI were in age group $<50$ years with a significant difference in age group distribution of patients $(\mathrm{P}=0.004)$. The male was higher than female in both adult patients with AKI and without AKI $(\mathrm{P}=0.384)$; Non-Saudi were higher than Saudi in both adult patients with AKI and without AKI $(\mathrm{P}=0.143)$; Surgery type was mostly coronary artery bypass graft $(\mathrm{CABG})$ in both adult patients with $\mathrm{AKI}$ and without AKI $(\mathrm{P}=0.235)$; valve replacement was mostly mechanical than biologic in both adult patients with AKI and without AKI (P $=0.588)$. The number of grafts in adult patients with AKI was 1 in $12.1 \%(\mathrm{n}=13), 2$ in $28.0 \%(\mathrm{n}=30), 3$ in $17.8 \%(\mathrm{n}=19)$ and 4 in $6.5 \%(\mathrm{n}=7)$; while graft numbers in patients without AKI were 1 in $7.5 \%(\mathrm{n}=20)$, 2 in $19.2 \%(\mathrm{n}=51), 3$ in $22.2 \%(\mathrm{n}=59)$ and 4 in $4.3 \%(\mathrm{n}=16)$ with significant difference between them (P $=0.046$ ). Adult patients with AKI were significantly higher than adult patients without AKI in median of $\mathrm{CPB}(\mathrm{P}=0.003)$, pre-existing hypertension $(57.9 \%$ versus $42.5 \%, \mathrm{P}=0.008)$, pre-operative creatinine level ( $\mathrm{P}$ $<0.0001)$, postoperative creatinine level $(\mathrm{P}<0.0001)$, difference between pre-and post-operative creatinine level $(\mathrm{P}<0.0001)$, percentage changes creatinine level $(\mathrm{P}<0.0001)$ and death within index hospitalization (13.1\% versus $2.6 \%, \mathrm{P}<0.0001)$. Stages of AKI were mostly stage I $(68.2 \%)$, then stage II $(18.7 \%)$, and lastly stage III (13.1\%) (Table 3). 
Table (2): Characteristics of pediatrics patients undergoing cardiac surgery according to the occurrence of acute kidney injury (AKI).

\begin{tabular}{|c|c|c|c|c|}
\hline Variables & $\begin{array}{l}\text { All patients }(\mathrm{n}= \\
568)\end{array}$ & $\operatorname{AKI}(\mathrm{n}=114)$ & No AKI $(\mathrm{n}=454)$ & Significance \\
\hline Age category & & & & 0.092 \\
\hline [?] 30 days & $69(12.1 \%)$ & $18(15.8 \%)$ & $51(11.2 \%)$ & \\
\hline $\begin{array}{l}>30 \text { days- }[?] 2 \\
\text { years }\end{array}$ & $329(57.9 \%)$ & $72(63.2 \%)$ & $257(56.6 \%)$ & \\
\hline$>2-<13$ years & $139(24.5 \%)$ & $21(18.4 \%)$ & $118(26.0 \%)$ & \\
\hline [?] $13-<18$ years & $31(5.5 \%)$ & $3(2.6 \%)$ & $28(6.2 \%)$ & \\
\hline Gender & & & & 0.600 \\
\hline Male & $312(54.9 \%)$ & $60(52.3 \%)$ & $252(55.5 \%)$ & \\
\hline Female & $256(45.1 \%)$ & $54(47.4 \%)$ & $202(44.5 \%)$ & \\
\hline Nationality & & & & 0.784 \\
\hline Saudi & $100(17.6 \%)$ & $21(18.4 \%)$ & $79(17.4 \%)$ & \\
\hline Non-Saudi & $468(82.4 \%)$ & $93(81.6 \%)$ & $375(82.6 \%)$ & \\
\hline $\begin{array}{l}\text { Cardiac } \\
\text { pulmonary bypass } \\
\text { (min) }\end{array}$ & $68(49.0-88.5)$ & $79.0(61.5-97.5)$ & $64.0(47.0-85.0)$ & 0.0001 \\
\hline $\begin{array}{l}\text { Aortic cross } \\
\text { clamp (min) }\end{array}$ & $48(31.0-64.0)$ & $57.0(42.0-70.5)$ & $45.0(29.0-63.0)$ & 0.0001 \\
\hline Case Urgency & & & & 0.891 \\
\hline Elective & $469(82.6 \%)$ & $95(83.3 \%)$ & $374(82.6 \%)$ & \\
\hline Emergent & $99(17.4 \%)$ & $19(16.7 \%)$ & $99(17.4 \%)$ & \\
\hline $\begin{array}{l}\text { Pre-operative } \\
\text { creatinine } \\
(\mathrm{mg} / \mathrm{dl})\end{array}$ & $0.33(0.25-0.44)$ & $0.24(0.19-0.32)$ & $0.35(0.27-0.46)$ & 0.0001 \\
\hline $\begin{array}{l}\text { Post-operative } \\
\text { creatinine } \\
(\mathrm{mg} / \mathrm{dl})\end{array}$ & $0.34(0.24-0.46)$ & $0.49(0.37-0.67)$ & $0.31(0.21-0.41)$ & 0.0001 \\
\hline $\begin{array}{l}\text { Difference } \\
\text { between Pre- and } \\
\text { Post- operative } \\
\text { creatinine } \\
(\mathrm{mg} / \mathrm{dl})\end{array}$ & $0.00(-0.10-0.11)$ & $0.24(0.16-0.36)$ & $-0.04(-0.12-0.03)$ & 0.0001 \\
\hline $\begin{array}{l}\text { Percentage } \\
\text { changes of } \\
\text { creatinine (\%) } \\
\text { Stages of acute } \\
\text { kidney injury }\end{array}$ & $100(71.98-135.25)$ & $\begin{array}{l}195.50 \\
(163.86-259.29)\end{array}$ & $\begin{array}{l}87.50 \\
(65.63-109.62)\end{array}$ & 0.0001 \\
\hline Stage I & - & $62(54.4 \%)$ & - & \\
\hline Stage II & - & $35(30.7 \%)$ & - & \\
\hline Stage III & - & $17(14.9 \%)$ & - & \\
\hline $\begin{array}{l}\text { Death within } \\
\text { index } \\
\text { hospitalization }\end{array}$ & $15(2.6 \%)$ & $8(7.0 \%)$ & $7(1.5 \%)$ & 0.004 \\
\hline
\end{tabular}

Data were expressed as Median (25-75 median percentiles) or frequency (\%) as appropriate. Stage I of AKI: Increase [?]0.3 mg/dL ([?]26.4 mmol/L), or Increase [?]150-200\% (1.5-2-fold) from baseline. Stage II of AKI: Increase $>200-300 \%$ (2-3-fold) from baseline. Stage III of AKI: Increase $>300 \%$ ( $>3$-fold) from baseline, or 
$\mathrm{SCr}$ to [?] $4 \mathrm{mg} / \mathrm{dL}$ ([?]354 mmol/L) with an acute increase [?]0.5 mg/dL ([?]44 mmol/L).

Table (3): Characteristics of adult patients undergoing cardiac surgery according to the occurrence of acute kidney injury (AKI).

\begin{tabular}{|c|c|c|c|c|}
\hline Variables & $\begin{array}{l}\text { Adult ([?] } 18 \text { years }) \\
(\mathrm{n}=373)\end{array}$ & AKI $(\mathrm{n}=107)$ & No AKI $(\mathrm{n}=266)$ & Significance \\
\hline Age category & & & & 0.004 \\
\hline$<50$ years & $114(30.6 \%)$ & $21(19.6 \%)$ & $93(35.0 \%)$ & \\
\hline $50-59$ years & $115(30.8 \%)$ & $33(30.8 \%)$ & $82(30.8 \%)$ & \\
\hline $60-69$ years & $106(28.4 \%)$ & $35(32.7 \%)$ & $71(26.7 \%)$ & \\
\hline [?] 70 years & $38(10.2 \%)$ & $18(16.8 \%)$ & $20(7.5 \%)$ & \\
\hline \multicolumn{5}{|l|}{ Gender } \\
\hline Male & $301(80.7 \%)$ & $83(77.6 \%)$ & $218(82.0 \%)$ & 0.384 \\
\hline Female & $72(19.3 \%)$ & $24(22.4 \%)$ & $48(18.0 \%)$ & \\
\hline Nationality & & & & 0.143 \\
\hline Saudi & $41(11.0 \%)$ & $16(15.0 \%)$ & $25(9.4 \%)$ & \\
\hline Non-Saudi & $332(89.0 \%)$ & $91(85.0 \%)$ & $241(90.6 \%)$ & \\
\hline Type of Surgery & & & & 0.235 \\
\hline Adult congenital & $92(24.7 \%)$ & $18(16.8 \%)$ & $74(27.8 \%)$ & \\
\hline Valve repair & $16(4.3 \%)$ & $5(4.7 \%)$ & $11(4.1 \%)$ & \\
\hline Valve replacement & $57(15.3 \%)$ & $15(14.0 \%)$ & $42(15.8 \%)$ & \\
\hline $\begin{array}{l}\text { coronary artery } \\
\text { bypass graft }\end{array}$ & $205(55.0 \%)$ & $68(63.6 \%)$ & $137(51.5 \%)$ & \\
\hline $\begin{array}{l}\text { Combined } \\
\text { (CABG+Valve } \\
\text { repair) }\end{array}$ & $1(0.3 \%)$ & - & $1(0.4 \%)$ & \\
\hline $\begin{array}{l}\text { Combined } \\
\text { (CABG+Valve } \\
\text { replacement) }\end{array}$ & $2(0.5 \%)$ & $1(0.9 \%)$ & $1(0.4 \%)$ & \\
\hline Valve type & & & & 0.588 \\
\hline Mechanical & $49(13.1 \%)$ & $12(11.2 \%)$ & $37(13.9 \%)$ & \\
\hline Biologic & $10(2.7 \%)$ & $4(3.7 \%)$ & $6(2.3 \%)$ & \\
\hline Number of grafts & & & & 0.046 \\
\hline 1 & $33(8.8 \%)$ & $13(12.1 \%)$ & $20(7.5 \%)$ & \\
\hline 2 & $81(21.7 \%)$ & $30(28.0 \%)$ & $51(19.2 \%)$ & \\
\hline 3 & $78(20.9 \%)$ & $19(17.8 \%)$ & $59(22.2 \%)$ & \\
\hline 4 & $16(4.3 \%)$ & $7(6.5 \%)$ & $9(3.4 \%)$ & \\
\hline $\begin{array}{l}\text { Cardiac } \\
\text { pulmonary bypass } \\
\text { (min) }\end{array}$ & $\begin{array}{l}112.00 \\
(89.50-138.00)\end{array}$ & $122.0(96.0-158.0)$ & $\begin{array}{l}108.5 \\
(87.0-130.25)\end{array}$ & 0.003 \\
\hline $\begin{array}{l}\text { Aortic cross } \\
\text { clamp (min) }\end{array}$ & $\begin{array}{l}67.50 \\
(54.00-92.00)\end{array}$ & $72.0(58.5-100.0)$ & $66.0(53.0-89.0)$ & 0.051 \\
\hline Case Urgency & & & & 0.384 \\
\hline Elective & $307(82.3 \%)$ & $92(86.0 \%)$ & $215(80.8 \%)$ & \\
\hline Emergent & $64(17.2 \%)$ & $15(14.0 \%)$ & $49(18.4 \%)$ & \\
\hline Urgent & $2(0.5 \%)$ & - & $2(0.8 \%)$ & \\
\hline Smoking & $93(24.9 \%)$ & $25(23.4 \%)$ & $68(25.6 \%)$ & 0.693 \\
\hline $\begin{array}{l}\text { Pre-existing } \\
\text { hypertension }\end{array}$ & $175(46.9 \%)$ & $62(57.9 \%)$ & $113(42.5 \%)$ & 0.008 \\
\hline $\begin{array}{l}\text { Pre-existing } \\
\text { diabetes mellitus }\end{array}$ & $147(39.4 \%)$ & $48(44.9 \%)$ & $99(37.2 \%)$ & 0.196 \\
\hline
\end{tabular}




\begin{tabular}{lllll}
$\begin{array}{l}\text { Pre-operative } \\
\text { creatinine } \\
(\mathrm{mg} / \mathrm{dl})\end{array}$ & $0.97(0.80-1.17)$ & $1.11(0.81-1.29)$ & $0.95(0.79-1.10)$ & 0.0001 \\
$\begin{array}{l}\text { Post-operative } \\
\text { creatinine } \\
(\mathrm{mg} / \mathrm{dl})\end{array}$ & $1.01(0.78-1.40)$ & $1.84(1.42-2.62)$ & $0.90(0.72-1.08)$ & 0.0001 \\
$\begin{array}{l}\text { Difference } \\
\text { between Pre- and }\end{array}$ & $0.06(-0.11-0.40)$ & $0.67(0.47-1.18)$ & $-0.04(-0.15-0.09)$ & 0.0001 \\
$\begin{array}{l}\text { Post- operative } \\
\text { creatinine } \\
\text { (mg/dl) }\end{array}$ & & & & \\
$\begin{array}{l}\text { Percentage } \\
\text { changes creatinine } \\
(\%)\end{array}$ & 106.17 & 162.71 & & 0.0001 \\
$\begin{array}{l}\text { Death within } \\
\text { index }\end{array}$ & $21(5.17-141.50)$ & $(147.91-223.58)$ & $(82.67-109.03)$ & 0.0001 \\
hospitalization & & $14(13.1 \%)$ & $7(2.6 \%)$ & \\
$\begin{array}{l}\text { Stages of AKI } \\
\text { Stage I }\end{array}$ & & & & \\
$\begin{array}{l}\text { Stage II } \\
\text { Stage III }\end{array}$ & & $73(68.2 \%)$ & & \\
\hline
\end{tabular}

Data were expressed as Median (25-75 median percentiles) or frequency (\%) as appropriate. Stage I of AKI: Increase [?]0.3 mg/dL ([?]26.4 mmol/L), or Increase [?]150-200\% (1.5-2-fold) from baseline. Stage II of AKI: Increase $>200-300 \%$ (2-3-fold) from baseline. Stage III of AKI: Increase $>300 \%$ ( $>3$-fold) from baseline, or $\mathrm{SCr}$ to [?] $4 \mathrm{mg} / \mathrm{dL}$ ([?]354 mmol/L) with an acute increase [?]0.5 mg/dL ([?]44 mmol/L).

Discussion

This study uniquely focuses on both pediatrics and adults to identify CSA-AKI risk factors to help in prevention. GFR is the best measure of kidney function, but it lacks specificity and sensitivity as a biomarker and SCr had been the main method to detect AKI. The main CSA-AKI predictive risk factors include age, perioperative GFR, lactate dehydrogenase (LDH), prothrombin time (PT), history of surgery, transfusion, cardiac arrhythmia, coronary heart disease (CHD), or chronic kidney disease (CKD), calcium channel blocker (CCB), proton pump inhibitors (PPI), non-steroidal anti-inflammatory drugs (NSAID), antibiotic or statin before surgery ${ }^{12}$. Obesity is an independent risk factor and oxidative stress may partially mediate this association ${ }^{13}$. Our study showed that younger age is a protective factor against CSA-AKI. The incidence in the pediatric patients was $(20.07 \%)$ compared to $28.68 \%$ in adults.

The reported incidence varies, according to AKI definition, between 1\%-30\%. We chose strict criteria that define AKI by increasing in SCr [?] $0.3 \mathrm{mg} / \mathrm{dL}$ above baseline, thus justifying the high incidence in our study $28.68 \%$ compared to others. CSA-AKI pathophysiology is not fully understood. it can be related to impaired renal reserve or decrease renal perfusion, reperfusion, inflammation, oxidative stress, toxins and hemolysis. Hemoglobin induced pigment nephropathy is another factor. Prophylactic sodium bicarbonate might help in prevention $^{14}$. Many studies showed that CSA-AKI is significantly related to the female gender, presence of Chronic obstructive pulmonary disease (COPD), diabetes mellitus (DM), peripheral vascular disease, renal impairment and congestive heart failure (CHF), valve surgery, case urgency, cardiogenic shock requiring intra-aortic balloon, left coronary insufficiency, length of ACX and CPB, off-pump versus on-pump surgery, non-pulsatile flow, hemolysis, and hemodilution ${ }^{12,15-17}$. Park and colleagues showed that off pump surgery has similar incidence of CSA-AKI to on pump ${ }^{18}$.

Urgency was not an important risk factor in our study. 
Our study showed insignificant relation to female gender, DM, type of surgery and case urgency. Age and hypertension were significant risk factors in our adults. In our study, the age group 60-69 years was the high-risk group.

In addition to morbidity burden, 30 days mortality or death within indexed hospitalization is significantly associated with CSA-AKI. in our study, this was $13.1 \%$ slightly lower than the reported literature between $15 \%-30 \%^{18,19}$. CSA-AKI is the most expensive complication especially when using RRT ${ }^{20,21}$. Our study like others showed that stage 1 is the most common type (68.2\%). Jiang and colleagues reported high mortality of CSA-AKI-RRT and recommend adjustment of the modifiable predictors to help in prevention ${ }^{21}$.

In pediatric group the incidence was $20.07 \%$ as per AKIN criteria. Krawczeski and colleagues reported an incidence of $42 \%$ using the same criteria ${ }^{22}$. The majority of our pediatric cases that developed CSA-AKI $(63.2 \%)$ were in the age group $>30$ days- [?]2 years. This age group is at greater risk of renal failure because of their limited physiological GFR before 2 years of age ${ }^{22,23}$. Our study showed that lower preoperative $\mathrm{SCr}$ in pediatric patients is a predictive risk factor. This might be due to age, bad nutrition, and smaller body weight.

Prevention

Nowadays, there is no pharmacological or nonpharmacological treatment of CSA-AKI. The available and approved management is confined to hemodynamic manipulations, intravenous resuscitation, balanced-salt fluid administration. Perioperative administration of sodium bicarbonate for the prevention of CSA-AKI is debated $^{25}$. Identification of high-risk group and prevention is the best and optimal strategy ${ }^{12-18,26,27}$.

Post cardiac surgery hyperglycemia is a common complication and is reported in 33.7-74\% in non-diabetic patients after cardiac surgery ${ }^{27}$. Novel biomarkers of kidney injury such as neutrophil gelatinase-associated lipocalin (NGAL), interleukin-18 (IL-18), cystatin C (CysC), have the potential to facilitate the early diagnosis of CSA-AKI ${ }^{29}$. Fenoldopam, a short acting dopamine A1 receptor agonist, may reduce RRT and mortality in critically ill patients and in patients undergoing cardiovascular surgery ${ }^{30}$.

We adopted a simple protocol for all our cardiac surgery patients to help in prevention table 4 .

Table4

\begin{tabular}{lll}
\hline Preoperatively & Intraoperatively & Postoperatively \\
\hline Avoiding or minimizing contrast media & Avoid prolonged CPB, ACX & Maintain hemodynamics (dobuta \\
Nephrotoxic drugs & Avoid hypotension & Avoid vasopressors \\
Optimize renal function & Maintain sufficient perfusion pressure & Balanced fluid and salt administr \\
Optimize hemodynamics' & & Early diagnosis and institution of \\
Rehydration & & Discontinuing angiotensin convert \\
Delay surgery if needed, Tight glycemic control & Tight glycemic control & Tight glycemic control \\
\hline
\end{tabular}

\section{Limitation of study}

The main limitation of this study being retrospective, small number and single center. Another limitation was not considering other criteria for AKI especially in pediatrics because of controversiality on choosing the definitive criteria for this group

Conclusion

CSA-AKI is a common and significant complication that affect the results of cardiac surgery both in adults and pediatrics. Prevention by preoperative identification of predictor risk factors and modification is the best strategy for management.

References 
1. Hoste EA, Cruz DN, Davenport A, et al. The epidemiology of cardiac surgery-associated acute kidney injury. Int J Artif Organs. 2008;31:158-165.

2. Wijeysundera DN, Karkouti K, Dupuis JY, et al. Derivation and validation of a simplified predictive index for renal replacement therapy after cardiac surgery. JAMA. 2007;297:1801-1809.

3. Mehta RH, Grab JD, O'Brien SM, et al. Bedside tool for predicting the risk of postoperative dialysis in patients undergoing cardiac surgery. Circulation. 2006;114:2208-16;quiz.

4. Thakar CV, Arrigain S, Worley S, Yared JP, Paganini EP. A clinical score to predict acute renal failure after cardiac surgery. J Am Soc Nephrol. 2005;16:162-168.

5. Lassnigg A, Schmidlin D, Mouhieddine M, et al. Minimal changes of serum creatinine predict prognosis in patients after cardiothoracic surgery: a prospective cohort study. J Am Soc Nephrol. 2004;15:1597-1605.

6. Uchino S, Kellum JA, Bellomo R, et al. Acute renal failure in critically ill patients: a multinational, multicenter study. JAMA. 2005;294:813-818.

7. Karkouti K, Wijeysundera DN, Yau TM, et al. Acute kidney injury after cardiac surgery: focus on modifiable risk factors. Circulation. 2009;119:495-502.

8. Thakar CV, Worley S, Arrigain S, Yared JP, Paganini EP. Influence of renal dysfunction on mortality after cardiac surgery: modifying effect of preoperative renal function. Kidney Int. 2005;67:1112- 1119 .

9. Lopez-Delgado JC EF, Torrado H, Rodríguez-Castro D, Carrio ML, Farrero E, Javierre C, et al. Influence of acute kidney injury on short- and long-term outcomes in patients undergoing cardiac surgery: risk factors and prognostic value of a modified RIFLE classification. Crit Care. 2013;17(16): R293. doi:210.1186/cc13159

10. Gomez H, Ince C, De Backer D, Pickkers P, Payen D, Hotchkiss J, et al. A unified theory of sepsisinduced acute kidney injury: inflammation, microcirculatory dysfunction, bioenergetics, and the tubular cell adaptation to injury. Shock. 2014;41(41):3-11.

11. Bellomo, Rinaldo, et al. "Acute Renal Failure - Definition, Outcome Measures, Animal Models, Fluid Therapy and Information Technology Needs: The Second International Consensus Conference of the Acute Dialysis Quality Initiative (ADQI) Group." Critical Care , vol. 8, no. 4, 2004, p. R204. Crossref , doi:10.1186/cc2872.

12. Harky A, Joshi M, Gupta S, Teoh WY, Gatta F, Snosi M. Acute Kidney Injury Associated with Cardiac Surgery: a Comprehensive Literature Review. Braz J Cardiovasc Surg . 2020;35(2):211-224.

13.Moon H, Lee Y, Kim S, Kim DK, Chin HJ, Joo KW, Kim YS, Na KY, Han SS. Differential signature of obesity in the relationship with acute kidney injury and mortality after coronary artery bypass grafting. Journal of Korean medical science. 2018 Nov 1;33(48)

14. Haase M, Haase-Fielitz A, Bagshaw SM, Ronco C, Bellomo R. Cardiopulmonary bypass-associated acute kidney injury: a pigment nephropathy? Contrib Nephrol. 2007;156:340-53.

15. Wang Y, Bellomo R. Cardiac surgery-associated acute kidney injury: risk factors, pathophysiology and treatment. Nat Rev Nephrol. 2017 Nov;13(11):697-711.

16. Guan C, Li C, Xu L, Zhen L, Zhang Y, Zhao L, Zhou B, Che L, Wang Y, Xu Y. Risk factors of cardiac surgery-associated acute kidney injury: development and validation of a perioperative predictive nomogram. J Nephrol. 2019 Dec;32(6):937-945.

17. O'Neal JB, Shaw AD, Billings FT 4th. Acute kidney injury following cardiac surgery: current understanding and future directions. Crit Care. 2016 Jul 4;20(1):187. doi: 10.1186/s13054-016-1352-z. PMID: 27373799; PMCID: PMC4931708

18. Vaschetto R, Groeneveld AB. An update on acute kidney injury after cardiac surgery. Acta Clinica Belgica. Supplementum, 2007, (2):380-384. 
19. Karim HM, Yunus M, Saikia MK, Kalita JP, Mandal M. Incidence and progression of cardiac surgeryassociated acute kidney injury and its relationship with bypass and cross clamp time. Ann Card Anaesth. 2017 Jan-Mar;20(1):22-27. doi: 10.4103/0971-9784.197823. PMID: 28074790; PMCID: PMC5290689.

20. Ronco C, Kellum JA, Bellomo R. Cardiac surgery-associated acute kidney injury. International Journal of Artificial Organs , 2008, 31:156-157.

21. Jiang W, Shen B, Wang Y, Xu J, Luo Z, Ding X, Teng J. Potentially Modifiable Predictors for Renal Replacement Therapy in Patients with Cardiac Surgery Associated-Acute Kidney Injury: a Propensity ScoreMatched Case-Control Study. Braz J Cardiovasc Surg. 2019 Jan-Feb;34(1):33-40.

22. Li S, Krawczeski CD, Zappitelli M, et al. Incidence, risk factors, and outcomes of acute kidney injury after pediatric cardiac surgery: a prospective multicenter study. Crit Care Med. 2011;39:1493-9

23. Cardoso B, Laranjo S, Gomes I, Freitas I, Trigo C, Fragata I, Fragata J, Pinto F. Insuficiência renal aguda no contexto de cirurgia cardíaca pediátrica: fatores de risco e prognóstico. Proposta de um modelo preditivo [Acute kidney injury after pediatric cardiac surgery: risk factors and outcomes. Proposal for a predictive model]. Rev Port Cardiol. 2016 Feb;35(2):99-104. Portuguese.

24. Gruberg L et al. The prognostic implications of further renal function deterioration within $48 \mathrm{~h}$ of interventional coronary procedures in patients with pre-existent chronic renal insufficiency. Journal of the American College of Cardiology , 2000, .1548-36:1542

25. Kim JH, Kim HJ, Kim JY, Ahn Hs, Ahn IM, Choe WJ, Lim CH. Meta-Analysis of Sodium Bicarbonate Therapy for Prevention of Cardiac Surgery-Associated Acute Kidney Injury. J Cardiothorac Vasc Anesth. 2015 Oct;29(5):1248-56.

26. Schetz M, Bove T, Morelli A, Mankad S, Ronco C, Kellum JA. Prevention of cardiac surgery-associated acute kidney injury. Int J Artif Organs. 2008 Feb;31(2):179-89

27. Meersch M, Schmidt C, Hoffmeier A, Van Aken H, Wempe C, Gerss J, Zarbock A. Prevention of cardiac surgery-associated AKI by implementing the KDIGO guidelines in high risk patients identified by biomarkers: the PrevAKI randomized controlled trial. Intensive Care Med. 2017 Nov;43(11):1551-1561. doi: 10.1007/s00134-016-4670-3. Epub 2017 Jan 21. Erratum in: Intensive Care Med. 2017 Mar 7;: PMID: 28110412; PMCID: PMC5633630..

28. Cheng H, Sun JZ, Ji FH, Liu H. Prevention and Treatment of Cardiac Surgery Associated Acute Kidney Injury. J Anesth Perioper Med. 2016 Jan;3(1):42-51.

29. Sandokji I, Greenberg JH. Novel biomarkers of acute kidney injury in children: an update on recent findings. Curr Opin Pediatr. 2020 Jun;32(3):354-359

30. Zangrillo A, Biondi-Zoccai GG, Frati E, Covello RD, Cabrini L, Guarracino F, Ruggeri L, Bove T, Bignami E, Landoni G. Fenoldopam and acute renal failure in cardiac surgery: a meta-analysis of randomized placebo-controlled trials. J Cardiothorac Vasc Anesth. 2012 Jun;26(3):407-13. 